\title{
KESALAHAN SINTAKSIS TULISAN MAHASISWA ASING PROGRAM STUDI PENDIDIKAN BAHASA INDONESIA UNIVERSITAS BINA DARMA
}

\author{
Andina Muchti, M.Pd. \\ Dosen Universitas Bina Darma \\ Jalan Jenderal Ahmad Yani No. 03 Palembang \\ Sur-el : andina.muchti@binadarma.ac.id
}

\section{Article info}

Article history:

Received: 8/11/2018

Revised : 9/11/2018

Accepted: 15/12/2018

\begin{abstract}
A B S T R A C T
Study has objectives, (1) describe the mistakes in the language in the field of syntax in the essay writing of foreign students in the regular class, and (2) describe the analysis of the mistakes in the language in the field of syntax in the essay writing of foreign students in the regular class in Bina Darma University. This research is a descriptive qualitative research. Sources of data in this study iswriting of foreign students in the regular class in UBD. The data is a form of language errors in the essay writting. Analyzed using a unified method and agih. Results can be divided into nine aspects, there are (1) sentence structure not standard, (2) sentence is ambiguous, (3) sentence is unclear, (4) diction is not appropriate in forming sentences, (5) contamination sentence, (6) coherence, (7) word redundant, (8) the word uptake used in a sentence, and (9) logic sentence.
\end{abstract}

Keywords:

bouquet, syntax,

linguistic fault

Kata Kunci:

karangan, sintaksis, kesalahan berbahasa
Penelitian ini memiliki tujuan, (1) mendeskripsikan bentuk kesalahan berbahasa bidang sintaksis dalam tulisan mahasiswa asing kelas regular Program Studi Pendidikan Bahasa Indonesia Universitas Bina Darma, dan (2) mendeskripsikan analisis bentuk kesalahan berbahasa bidang sintaksis dalam tulisan mahasiswa asing kelas regular Program Studi Pendidikan Bahasa Indonesia Universitas Bina Darma. Jenis penelitian ini adalah penelitian kualitatif deskriptif dengansumber data tulisan mahasiswa asing kelas regular Prodi Pendidikan Bahasa Indonesia UBD.Data berupa bentuk kesalahan berbahasa pada tulisan mahasiswa asing.Teknik analisis data menggunakan metode padan dan agih. Hasil penelitian inidapat dibagi menjadi 9 aspek, yaitu (1) kalimat berstruktur tidak baku, (2) kalimat ambigu, (3) kalimat yang tidak jelas, (4) diksi yang tidak tepat dalam membentuk kalimat, (5) kontaminasi kalimat, (6) koherensi, (7) penggunaan kata mubazir, (8) kata serapan yang digunakan dalam kalimat, dan (9) logika kalimat. 


\section{JURNAL ILMIAH \\ BINA EDUKASI \\ ISSN 1979-8598 E-ISSN: 2655-8378 \\ http://journal.binadarma.ac.id/index.php/jurnalbinaedukasi \\ Vol. 11, No. 2, Desember 2018, 99-108}

\section{PENDAHULUAN}

Secara umum, bahasa Indonesia sudah diketahui sebagai alat berkomunikasi. Dalam setiap situasi memungkinkan seseorang memilih variasi bahasa yang akan digunakannya. Berbagai faktor juga menentukan pemilihan tersebut, seperti penulis, pembaca, pokok pembicaraan, dan sarana. Dalam berbahasa Indonesia, tingkat kesadaran dan kepatuhan akan kaidah berbahasa secara jelas terlukiskan melalui perilaku berbahasa, baik ketika kita menggunakan bahasa Indonesia secara lisan maupun tulisan.

Salah satu fenomena penerapan bahasa yang paling aktif adalah di bidang pendidikan. Pelajaran Bahasa Indonesia dalam dunia pendidikan dapat membantu siswa atau mahasiswa untuk mengerti dan memahami berbagai kaidah bahasa, penggunaan bahasa, dan tuturan secara langsung dan tidak langsung, terutama pada saat seseorang akan berkomunikasi dengan manusia lainnya di kehidupan sehari-hari. Pada kehidupan berkelompok pun, ilmu bahasa juga sangat berguna saat berkomunikasi dengan orang lain. Oleh karena itu, bahasa sangat berperan penting bagi kehidupan bermasyarakat, dan juga pastinya di lingkungan pendidikan. Tak terlepas oleh mahasiswa asing yang menempuh pendidikan di lingkungan masyarakat Indonesia pada umumnya juga pasti harus menggunakan bahasa Indonesia yang baik dan benar. Mahasiswa asing yang menempuh pendidikan di kelas regular pastinya akan mengalami beberapa kendala terutama pada bidang bahasa yang juga tak bisa dilepaskan dari kaidah-kaidah bahasa Indonesia yang berlaku.

Untuk itu, pelajaran Bahasa Indonesia sangat dibutuhkan di setiap tingkatan sekolah, mulai dari SD, SMP, SMA hingga Perguruan Tinggi. Hal itu dilakukan agar semua peserta didik dapat memperoleh pengetahuan yang lebih luas dalam mempelajari bahasa. Mata pelajaran Bahasa Indonesia tidak hanya mempelajari seluk beluk tentang bahasa pada umumnya, tetapi juga tentang tataran fonologi, morfologi, sintaksis, dan semantik yang lebih luas lagi. Bahasa Indonesia juga menjelasakan tentang tujuan di luar bahasa yang lebih luas.

Bahasa Indonesia memiliki dua fungsi dan kedudukan di Indonesia, yakni sebagai (1) bahasa nasional, dan (2) bahasa negara. Dalam kedudukannya sebagai bahasa nasional, bahasa Indonesia memiliki beberapa fungsi, antara lain sebagai, lambang kebanggaan nasional, lambang identitas nasional, alat pemersatu berbagai masyarakat yang berbeda-beda latar belakang sosial, budaya, dan bahasa, dan alat perhubungan antarbudaya dan daerah, Setyawati (2002:01).

Berdasarkan hasil observasi di Program Studi Pendidikan Bahasa Indonesia Universitas Bina Darma, paling banyak terdapat mahasiswa asing yang berasal dari berbagai negara yang tersebar di berbagai tingkatan. Mahasiswa-mahasiswa itu diwajibkan mengikuti perkuliahan 


\section{JURNAL ILMIAH}

BINA EDUKASI

ISSN 1979-8598 E-ISSN: 2655-8378

http://journal.binadarma.ac.id/index.php/jurnalbinaedukasi

Vol. 11, No. 2, Desember 2018, 99-108

sama seperti mahasiswa lainnya yang berasal dari negara Indonesia. Mereka semua dianggap sama dalam kemampuan berbahasa, baik kemampuan mendengar, berbicara, membaca, maupun menulis. Hanya saja, dari hasil pengamatan yang telah dilakukan, ternyata kemampuan berbahasa Indonesia mahasiswa asing tersebut tidak sebaik mahasiswa lainnya di kelas regular. Walaupun, kemampuan menuangkan ide dalam tulisan, sebagian dari mereka memiliki kelebihan dibandingkan mahasiswa lainnya yang berasal dari Indonesia.

Jika diperhatikan lebih dalam,kurangnya kemampuang pengunaan Bahasa Indonesia oleh mahasiswa asing itu karena melekatnya bahasa ibu yang dimiliki. Selain itu, pola dan susunan kalimat dalam bahasa ibu masing-masing mahasiswa itu berbeda dengan pola dan susunan kalimat bahasa Indonesia.

Hasil belajar beberapa mahasiswa asing di Program Studi Pendidikan Bahasa Indonesia kelas regular Universitas Bina Darma ini termasuk dalam kategori tinggi. Namun, beberapa mahasiswa asing lainnya yang terdapat di kelas regular Program Studi Pendidikan Bahasa Indonesia masuk dalam kategori sedang dan rendah. Pada kenyataannya mahasiswa asing kelas regular Program Studi Pendidikan Bahasa Indonesia mampu mengikuti proses pembelajaran dengan baik selama dosen menjelaskan di dalam kelas meskipun terkadang memiliki beberapa kendala berbahasa.Kendala berbahasa itu mereka siasati dengan menggunakan bantuan kamus bahasa ibu mereka.

Ada lima mahasiswa asing yang terdapat di kelas regular Program Studi Pendidikan Bahasa Indonesia, Universitas Bina Darma. Mereka tersebar di semester satu, lima, dan tujuh. Berikut ini daftar asal negara mahasiswa asing kelas reguler Program Studi Pendidikan Bahasa Indonesia, Universitas Bina Darma.

1. Mahasiswa semester 7 yang berasal dari Amerika Serikat.

2. Mahasiswa semester 5 yang berasal dari Korea Selatan.

3. Mahasiswa semester 1 yang berasal dari Mexico.

4. Mahasiswa semester 1 yang berasal dari Korea Selatan.

5. Mahasiswa semester 1 yang berasal dari Korea Selatan.

Di dalam dunia pendidikan menulis akan tetap berharga, sebab menulis membantu seseorang berpikir lebih mudah. Dengan menulis, manusia dapat menuangkan ide dan pikirannya dengan lebih lengkap, terstruktur, dan terperinci. Menulis adalah suatu alat yang sangat ampuh dalam belajar. Dengan sendirinya menulis memainkan peran yang sangat penting dalam dunia pendidikan.

Semi, Atar (2007: 14) dalam bukunya mengungkapkan pengertian menulis, yaitu suatu proses kreatif memindahkan gagasan ke dalam lambang-lambang tulisan. Lebih lanjut Nurgiantoro (1988: 273) menyatakan bahwa menulis adalah aktivitas aktif produktif, yaitu aktivitas menghasilkan bahasa. 


\section{JURNAL ILMIAH \\ BINA EDUKASI \\ ISSN 1979-8598 E-ISSN: 2655-8378 \\ http://journal.binadarma.ac.id/index.php/jurnalbinaedukasi \\ Vol. 11, No. 2, Desember 2018, 99-108}

Sebuhungan dengan latar belakang di atas penulis melakukan penelitian mengenai analisis kesalahan berbahasa pada bidang sintaksis pada tulisan mahasiswa asing di kelas reguler Program Studi Pendidikan Bahasa Indonesia Universitas Bina Darma. Hasil kemampuan menulis di bidang sintaksis atau penyusunan kalimat efektif mahasiswa akan terlihat saat mahasiswa diberi tugas menuliskan sebuah karangan berdasarkan pemikirannya apakah kalimat yang ditulis sudah memenuhi kaidah kebahasaan yang baik dan benar atau belum.

Penulis berharap penelitian ini dapat menjadi rencana selanjutnya untuk mengembangkan bahan pelajaran bahasa Indonesiayang baik dan benar di lingkungan pendidikan di setiap jenjang. Pada penelitian ini, penulis melihat bentuk kesalahan berbahasa pada bidang sintaksis mahasiswa yang menjadi pelajaran penting dalam kegiatan menulis. Diharapkan mahasiswa mampu menuangkan gagasan dan pikirannya dalam bentuk tulisan dengan memerhatikan tata bahasa dan stuktur sintaksi terutama pada penggunaan kalimat efektif.

Oleh karena itu, mahasiswa harus mempelajari penggunaan bahasa yang baik dan benar atau kata yang baku dalam membuat kalimat. Fokus kajian dalam penelitian ini adalah (1) bagaimana bentuk kesalahan berbahasa pada bidang sintaksis dalam tulisan mahasiswa asing di kelas reguler Program Studi Pendidikan Bahasa Indonesia Universitas Bina Darma, dan (2) apa penyebab terjadinya bentuk kesalahan berbahasa pada bidang sintaksis dalam tulisan mahasiswa asing di kelas reguler Program Studi Pendidikan Bahasa Indonesia Universitas Bina Darma. Penelitian ini bertujuan untuk (1) mendeskripsikan dan menjelaskan jenis bentuk kesalahan berbahasa pada bidang sintaksis dalam tulisan mahasiswa asing di kelas reguler Program Studi Pendidikan Bahasa Indonesia Universitas Bina Darma, dan (2) mendeskripsikan dan menjelaskan penyebab terjadinya bentuk kesalahan berbahasa pada bidang sintaksis dalam tulisan mahasiswa asing di kelas reguler Program Studi Pendidikan Bahasa Indonesia Universitas Bina Darma.

Penelitian serupa pernah dilakukan oleh Mukaromah (2009) yang berjudul "Penggunaan Bentuk Mubazir pada Karangan Deskripsi Siswa Kelas VII SMP Negeri 1 Mojogedang Tahun Ajaran 2008/2009". Penelitian serupa pernah dilakukan pada tahun 2015, berjudul "Kesalahan Sintaksis Bahasa Jepang Tulis Mahasiswa Sastra Jepang Universitas Sumatera Utara". Penelitian-penelitian tersebut relevan dengan penelitian ini, yaitu mengkaji kesalahan berbahasa bidang sintaksis pada tulisan siswa. 


\section{JURNAL ILMIAH}

BINA EDUKASI

ISSN 1979-8598 E-ISSN: 2655-8378

http://journal.binadarma.ac.id/index.php/jurnalbinaedukasi

Vol. 11, No. 2, Desember 2018, 99-108

\section{METODOLOGI PENELITIAN}

\subsection{Sintaksis dan Bidang Kajiannya}

Istilah sintaksis (Belanda, syntaxis) ialah bagian atau cabang dari ilmu bahasa yang membicarakan seluk beluk wacana, kalimat, klausa, dan frase (Ramlan, 2001:18). Menurut Verhaar (2006: 5) sintaksis merupakan cabang ilmu bahasa yang membicarakan seluk beluk wacana, kalimat, klausa, dan frase, berbeda dengan morfologi yang membicarakan seluk beluk kata dan morfem. Dari pengertian itu dapat diketahui bahwa bidang garapan sintaksis tidak hanya terdiri atas kalimat, klausa, dan frasa, tetapi juga wacana.

Kridalaksana (1982:154) mengatakan bahwa sintaksis adalah (1) pengaturan dan hubungan antara kata dengan kata, atau dengan satuan-satuan yang lebih besar, atau antara satuan-satuan yang lebih besar itu dalam bahasa, (2) subsistem bahasa yang mencangkup hal tersebut (sering dianggap bagian dari gramatika; bagian lain adalah morfologi), dan (3) cabang linguistik yang mempelajari hal tersebut.

Kesalahan sintaksis adalah kesalahan atau penyimpangan struktur frasa, klausa, atau kalimat, serta ketidaktepatan pemakaian partikel.Analisis kesalahan dalam bidang tata kalimat menyangkut urutan kata, kepaduan, susunan frasa, kepaduan kalimat, dan logika kalimat.Hal itu jelas dikatakan oleh Tarigan (2008:73) dan Semi (2007:13) mengemukakan bahwa kesalahan berbahasa dalam bidang sintaksis meliputi kesalahan frasa, kesalahan klausa, dan kesalahan kalimat.

Sebab-sebab terjadinya kesalahan sintaksis terbagi menjadi sembilan kesalahan di antaranya ( 1) kalimat berstruktur tidak baku, (2) kalimat ambigu, (3) kalimat yang tidak jelas, (4) diksi yang tidak tepat dalam membentuk kalimat, (5) kontaminasi kalimat, (6) koherensi, (7) penggunaan kata mubazir, (8) kata serapan yang tidak tepat dalam membentuk kalimat, dan (9) logika kalimat.

Tulisan atau wacana dapat dikembangkan dalam empat bentuk, yaitu (1) narasi, merupakan bentuk percakapan atau tulisan yang bertujuan menyampaikan atau menceritakan rangkaian peristiwa atau pengalaman manusia berdasarkan perkembangan dan waktu ke waktu; (2) eksposisi dalah tulisan yang bertujuan menjelaskan atau memberikan informasi tentang sesuatu; (3) deskripsi adalah tulisan yang tujuannya memberikan perincian atau detail tentang objek sehingga dapat member pengaruh pada sensivitas dan imajinasi pembaca atau pendengar, bagaikan mereka ikut mendengar, melihat, merasakan, atau mengalami langsung objek tersebut dan (4) argumentasi adalah tulisan yang bertujuan meyakinkan atau membujuk pembaca tentang kebenaran pendapat atau pernyataan penulis. 


\section{JURNAL ILMIAH}

BINA EDUKASI

ISSN 1979-8598 E-ISSN: 2655-8378

http://journal.binadarma.ac.id/index.php/jurnalbinaedukasi

Vol. 11, No. 2, Desember 2018, 99-108

\subsection{Metode Penelitian}

Penelitian ini merupakan jenis penelitian deskriptif kualitatif. Fakta-fakta yang dideskripsikan dalam penelitian ini berupa bentuk kesalahan berbahasa bidang sintaksis dalam tulisan mahasiswa asing di kelas reguler Program Studi Pendidikan Bahasa Indonesia Universitas Bina Darma.

Sumber data adalah subjek dari mana asal data penelitian diperoleh. Apabila peneliti misalnya menggunakan koesioner atau wawancara dalam pengumpulan datanya, maka sumber data disebut responden, yaitu orang yang merespon atau menjawab pertanyaan, baik tertulis maupun lisan, Suwarjeni (2014; 73).

Data dalam penelitian ini berupa bentuk kesalahan berbahasa pada bidang sintaksis dalam tulisan mahasiswa asing di kelas reguler Program Studi Pendidikan Bahasa Indonesia Universitas Bina Darma.Selanjutnya, sumber data dalam penelitian ini adalah tulisan mahasiswa asing di kelas reguler Program Studi Pendidikan Bahasa Indonesia Universitas Bina Darma.

Teknik mengumpulan data yang digunakan dalam penelitian ini adalah observasi dan studi dokumen. Penulis hadir di kelas sebagai dosen untuk melakukan observasi mengenai kondisi lingkungan kelas dan proses pembelajaran mahasiswa selama perkuliahan berlangsung. Setelah itu, pengumpulan data dilanjutkan dengan studi dokumentasi.

\section{HASIL DAN PEMBAHASAN}

Berdasarkan temuan-temuan didapatkan bentuk kesalahan berbahasa pada bidang sintaksis dalam tulisan mahasiswa asing di kelas reguler Program Studi Pendidikan Bahasa Indonesia Universitas Bina Darma.Selanjutnya, temuan-temuan tersebut akan dideskripsikan berikut ini.

\subsection{Kalimat Berstruktur tidak Baku}

(1) Membaca menawarkan kesempatan menjelajah ide-ide baru yang mungkin kita tidak akan pikir sendiri.

Kalimat (1) merupakan kalimat berstruktur tidak baku yang dibuat oleh mahasiswa asing di kelas reguler Program Studi Pendidikan Bahasa Indonesia. Struktur atau susunan kata yang terdapat pada tulisan ini, yaitu mungkin kita tidak akan pikir sendiri tidak tepat. Bentuk yang benar seharusnya Yang mungkin tidak pernah kita pikirkan.

Selain itu, struktur kata menjelajah tidak baku karena kehilangan salah satu proses afiksasi akhiran $-i$ yang seharusnya menjadi menjelajahi. Sehingga kalimat lengkapnya akan 


\section{JURNAL ILMIAH}

BINA EDUKASI

ISSN 1979-8598 E-ISSN: 2655-8378

http://journal.binadarma.ac.id/index.php/jurnalbinaedukasi

Vol. 11, No. 2, Desember 2018, 99-108

menjadi Membaca menawarkan kesempatan untuk menjelajahi ide-ide baru yang mungkin tidak pernah kita pikirkan.

(2a) Karena itu, kita perlu beberapa prinsip yang kita bisa mengunakan untuk memilih dengan baik.

Struktur kata perlu tidak baku karena kehilangan salah satu proses afiksasi akhiran mekan yang seharusnya menjadi memerlukan. Selain itu pada kata memilih yang kehilangan partikel -nya sehingga menjadi memilihnya.

(3a) Untuk memilih dengan baik, harus pikir kalau bahan itu pantas dibaca.

Kalimat (3) merupakan kalimat berstruktur tidak baku karena dalam kalimat itu kehilangan fungsi subjek (S). Siapa dan apa yang berperan untuk memilih dan berpikir dalam kalimat itu. Sehingga kalimat yang benar adalah sebagai berikut Untuk memilih bahan bacaan dengan baik, kita harus pikirkan bahwa bahan bacaan itu pantas dibaca.

\subsection{Kalimat Ambigu}

Dalam tahapan klasifikasi data kalimat ambigu terdapat bentuk kesalahan berupa makna ganda seperti pada kalimat di bawah ini.

(2b) Karena itu, kita perlu beberapa prinsip yang kita bisa mengunakan untuk memilih dengan baik.

Kalimat (2b) juga merupakan kalimat berstruktur tidak baku yang dibuat oleh mahasiswa asing di kelas reguler Program Studi Pendidikan Bahasa Indonesia. Struktur atau susunan kata yang terdapat pada tulisan ini, yaitu... yang kita bisa mengunakan.... Susunan atau pun struktur pada kalimat itu tidak jelas sehingga dapat menimbulkan makna yang berbeda atau ambigu. Kalimat yang seharusnya ...yang bisa kita gunakan.... Sehingga kalimat lengkapnya akan menjadi oleh karena itu, kita memerlukan beberapa prinsip yang bisa kita gunakan untuk memilihnya dengan baik.

\subsection{Kalimat Yang Tidak Jelas}

(3) ada banyak bahan bacaan yang menawarkan kesempatan "mengalaman" tempat dan masa yang di luar pengalaman hidup kita.

Kalimat (3) tidak jelas maknaknya karena ada unsur kata yang tidak baku pada penulisan kalimat tersebut dan membingungkan. Kata mengalaman tidak gramatikal, sehingga seharusnya diganti dengan kata pengalaman.Selain itu, pada frasa yang di luar pengalaman hidup kita juga membingungkan, apakah masuk ke ladam perluasan objek atau menggantikan fungsi keterangan (K).jika itu merupakan perluasan (O) maka kalimat menjadi tidak jelas, sedangkan jika merupakan (K) seharusnya kata yang dihilangkan. Oleh karena itu, bentuk yang benar pada data tersebut sebagai berikut. 


\section{JURNAL ILMIAH}

BINA EDUKASI

ISSN 1979-8598 E-ISSN: 2655-8378

http://journal.binadarma.ac.id/index.php/jurnalbinaedukasi

Vol. 11, No. 2, Desember 2018, 99-108

Banyak bahan bacaan yang menawarkan kesempatan "pengalaman" selain dari pengalaman yang sudah kita lalui dalam hidup.

\subsection{Diksi yang tidak Tepat dalam Membentuk Kalimat}

(3b) Untuk memilih dengan baik, harus pikir kalau bahan itu pantas dibaca.

Kalimat (3b) pilihan kata yang digunakan tidak tepat dan masih menggunakan kata-kata tutur yang sering diucapkan saat berkomunikasi.Kata kalau merupakan kata penghubung untuk menandai syarat atau dapat digantikan dengan kata seandainya. Sementara pada kalimat itu tidak bermaksud untuk menandai sebuah persyaratan dan tidak juga dapat digantikan dengan kata seandainya.Kata yang tepat untuk menggantukannya adalah bahwa, karena kata iru menunjukkan penjelasan.Sehingga kalimat yang benar adalah sebagai berikut.Untuk memilih bahan bacaan dengan baik, kita harus pikirkan bahwa bahan bacaan itu pantas dibaca.

\subsection{Kontaminasi Kalimat}

Tidak terdapat kesalahan penulisan kalimat yang mengandung unsur kontaminasi kalimat pada tulisan mahasiswa asing di kelas reguler Program Studi Pendidikan Bahasa Indonesia di Universitas Bina Darma.

\subsection{Koherensi}

(6) Kita harus membaca luas dan pilih bahan bacaan dengan baik.

Kalimat (6) tidak koheren karena hubungan membaca denganluas dan pilih tidak padu. Kata membaca menyatakan unsur $\mathrm{P}$ dan seharusnya setelah $\mathrm{P}$ terdapat $\mathrm{O}$ disisipi aspek kata untuk menjelaskan $\mathrm{P}$, dengan adanya kata luas dan pilih, menunjukkan bahwa kalimat itu tidak koheren. Fungsi kata luas dan pilih menjadi kabur.Kata tersebut dan sekali sebaiknya dihilangkan dan diganti dengan kata yang lebih logis untuk memadukan sebuah kalimat agar efektif.Oleh karena itu, bentuk benar sebagai berikut. (6) Kita harus membaca lebih luas dan memilih bahan bacan dengan baik.

\subsection{Penggunaan Kata Mubazir}

(7) Kalau bahan itu bermanfaat bagi kita, merupakan keindahan, dan bermoral, jadi bahan itu merupakan karya yang pantas dibaca.

Penggunaan kata merupakan pada kalimat (7) menjadikan susunan kata yang diletakkan bertele-tele atau tidak hemat, lebih tepatnya menggunakan kata mubazir yang tidak diperlukan. Pada kalimat itu tudak diperlukan kata merupakan dalam membentuk kalimat-kalimat tersebut. Jika kata tersebut masih diletakkan di awal frasa keindahan sebagai penegasan ataupun penjelasan, maka akan menimbulkan kalimat menjadi tidak hemat. Selain itu kata jadi yang 


\section{JURNAL ILMIAH \\ BINA EDUKASI \\ ISSN 1979-8598 E-ISSN: 2655-8378 \\ http://journal.binadarma.ac.id/index.php/jurnalbinaedukasi \\ Vol. 11, No. 2, Desember 2018, 99-108}

terdapat di antara kata bermoral dan bahan itu juga merupakan mubazir kata atau dengan kata lain pemborosan kata. Sebaiknya kata jadi dihilangkan saja.Oleh karena itu, supaya kalimat menjadi lebih efektif dan mudah dipahamibentuk benar pada kalimat tersebut menjadi Kalau bahan itu bermanfaat, berkeindahan, dan bermoral, bahan itu merupakan karya yang pantas dibaca.

\subsection{Kata Serapan yang Digunakan dalam Kalimat}

Tidak terdapat kesalahan penulisan kalimat yang mengandung unsur kata serapan yang digunakan dalam kalimat pada tulisan mahasiswa asing di kelas reguler Program Studi Pendidikan Bahasa Indonesia di Universitas Bina Darma.

\subsection{Logika kalimat}

(9) Penelitian ini dikemukakan untuk mengambil kesempatan itu.

Kalimat (9) termasuk kalimat yang tidak logis karena terdapat klausa penelitian ini dikemukakan yang tidak masuk akal.Penelitian tidak dapat dikemukakan, biasanya penelitian berisi penjelasan.Sehingga seharusnya klausa yang benar adalah penelitian ini dijelaskan, maka maknanya lebih dapat diterimah oleh akal.Selain itu kata kemukakan adalah kata yang tidak gramatikal atau tidak sesuai dengan tata bahasa Indonesia. Oleh karena itu kalimat yang benar adalah sebagai berikut.Penelitian ini dijelaskan untuk mengambil kesempatan itu.

Diadakan penelitian mengenai kesalahan berbahasa khususnya pada bidang sintaksis ini untuk mengetahui sejauh mana tingkat kemahiran berbahasa mahasiswa asing di kelas reguler Program Studi Pendidikan Bahasa Indonesia Universitas Bina Darma.

Pada mata kuliah menulis terdapat pelajaran mengenai menulis karangan, essay, artikel, dan yang lainnya yang menuntut mahasiswa untuk lebih aktif dan produktif dalam kegiatan menulis.Aktif dan produktif itu juga harus sejalan dengan kaidah-kaidah yang berlaku dalam tata bahasa Indonesia, termasuk pada struktur sintaksis. Dalam hal ini juga dapat dijadikan bahan evaluasi oleh dosen dan mahasiswa, supaya mampu memperbaiki kesalahan-kesalahan saat mempelajari bidang kebahasaan.Hasil yang dicapai pada penelitian ini adalah dapat menambah kemampuan berbahasa saat menulis sebuah wacana maupun karangan dan menambah kekayaan kosa kata mahasiswa asing.Jadi, mahasiswa lebih berhati-hati saat membuat kalimat agar tidak terjadi kesalahan yang berulang.

Berdasarkan konteks artikel di atas dilatarbelakangi oleh bentuk kesalahan berhasa bidang sintaksis dalam tulisan mahasiswa asing di kelas reguler Program Studi Pendidikan Bahasa Indonesia Universitas Bina Darma mengenai kesalahan penggunaan kalimat berstruktur tidak baku, diksi yang tidak tepat dalam membentuk kalimat, dan kemubaziran dalam menulis 


\section{JURNAL ILMIAH \\ BINA EDUKASI \\ ISSN 1979-8598 E-ISSN: 2655-8378 \\ http://journal.binadarma.ac.id/index.php/jurnalbinaedukasi \\ Vol. 11, No. 2, Desember 2018, 99-108}

sebuah kalimat yang efektif, koherensi, dan logika kalimat.Sementara itu, tidak terdapat kesalahan pada kontaminasi kalimat dan kata serapan yang digunakan dalam kalimat.

\section{SIMPULAN}

Berdasarkan hasil analisis data dan pembahasan yang telah disajikan oleh penulis mengenai kesalahan berbahasa dalam bidang sintaksis dalam tulisan mahasiswa asing di kelas reguler Program Studi Pendidikan Bahasa Indonesia Universitas Bina Darma, dapat disimpulkan bahwa bentuk kesalahan pada bidang sintaksis dalam menulis karangan deskripsi terbagi menjadi sembilan bentuk kesalahan yaitu, pertama kalimat berstruktur tidak baku terdapat 13 kesalahan, kedua kalimat ambigu 11 kesalahan, ketiga kalimat yang tidak jelas 11 kesalahan, keempat diksi yang tidak tepat dalam membentuk kalimat 11 kesalahan, kelima koherensi 10 kesalahan, keenam kata mubazir 10 kesalahan, ketujuhkesalahan logika kalimat terdapat 8 kesalahan. Sementara itu, tidak terdapat kesalahan pada kontaminasi kalimat dan kata serapan yang digunakan dalam kalimat.

\section{DAFTAR PUSTAKA}

Kridalaksana, Harimurti. (1982). Kamus Linguistik. Jakarta: PT Gramedia.

Mukaromah, Fajar Hidayatun. (2009). "Penggunaan Bentuk Mubazir pada Karangan Deskripsi Siswa Kelas VII SMP Negeri 1 Mojogedang Tahun Ajaran 2008/2009”. Skripsi thesis. Surakarta. Fakultas Keguruan dan Ilmu Pendidikan, UMS. http://eprints.ums.ac.id/4450/ diunduh tanggal 13 Juni 2016 pukul 10.00 WIB.

Nurgiantoro, Burhan. (1988). Dasar-dasar Pengembangan Kurikulum Sekolah, Sebuah Pengantar Teoretis dan Pelaksanaan. Yogyakarta:BPFE.

Ramlan. (2001). Sintaksis. Yogyakarta: CV Karyono.

Semi, Atar. (2007). Dasar-Dasar Keterampilan Menulis.Bandung: Angkasa.

Setyawati, Nanik. (2002). Analisis Kesalahan Berbahasa Indonesia. Surakarta: Yuma Pustaka.

Sujarweni, V Wiratno. (2014). Metode Penelitian Lengkap Praktis dan Mudah Dipahami. Pustakabarupress: Yogyakarta.

Tarigan, H. G. (2008). Menulis Sebagai Suatu Keterampilan Berbahasa. Bandung: Angkasa.

Verhaar, J.W.M. (2006).Asas-asas Linguistik. Yogyakarta: Gadjah Mada University Press. 